\title{
Construction of School Culture System Based on Immersion Media
}

\author{
Xuanlin Li ${ }^{1}$, Qiqi Tan $^{2}$ \\ ${ }^{1,2}$ Chongqing University of Education, Chongqing, 400065, China
}

Keywords: School culture, Immersion media, Cultural system construction.

\begin{abstract}
Schools, as important places to create and spread knowledge, have unique cultural attributes. The Schools environment, classrooms, motto and books are all carriers of its culture. In the new era, we try to build the new school culture environment which combining books, classroom, landscape with internet technology and VR/AR contents by " Internet +" and " Immersion media". Using H5 technology and VR/AR technology to build immersive school culture system is the new direction of school culture development in the future.
\end{abstract}

\section{Introduction}

At present, various enterprise tycoons launch CR products. With great promotion of refresh rate and screen resolution, and continuous improvement of input equipment in posture correction, accuracy and delay, VR technology becomes mature day by day. Besides, equipment cost continues to drop, and basic VR products swarm into the market. People's application requirements for VR are met. Thus, VR application leaps to a new step, and teaching development is confronted with a new opportunity in the new age[3]. Therefore, under the influence of "internet +" thinking, H5 technology and VR technology are applied to combine traditional school culture and form the cultural system based on immersive media, which is a new direction of future school culture development.

\section{Necessity of constructing school culture system in "new age"}

School culture is the sum of material wealth and spiritual wealth created in school running process. To be specific, school culture refers to the sum of school running aim, value, school style and tradition, behavior norm and regulations which are formed by educational practice and jointly followed by both teachers and students, as well as various material carriers of the above content. School culture mainly includes physical and spiritual environment, and cultural atmosphere specially owned by schools. In April 2006, Ministry of Education issued the Notice about Strongly Enhancing Campus Culture Construction of Primary and Middle Schools, and required enhancement of campus culture construction of primary and middle schools ${ }^{[2]}$, and construction of favorable learning style, teaching style and school style. The development of school culture has entered a new stage.

The combination of various new techniques and education has become an important development direction of schools. As "big data, intelligence, mobile internet and cloud computing” are combined with various teaching activities, all kinds of teaching equipment and functions are widely applied in each field of schools. Creative culture, maker education and subject exploration become important components of school culture. How is school culture system combined with new technical means to form new systems? This becomes the development emphasis of school culture in the new age.

\section{Problems of traditional school culture}

Traditional school culture includes explicit material culture and implicit connotation culture. Explicit material culture mainly refers to some visual material cultures we can see and feel, including visual culture, indoor culture, and outdoor culture. Implicit connotation culture refers to inherent spiritual culture of a school, including idea, text and activities between teachers and students. It is invisible cultural connotation, school running thought, behavior norm and rule. Before constructing 
school culture system with new techniques, we need to analyze the existing problems so as to lay a foundation for the construction.

\subsection{Dominate culture of schools becomes formalistic}

Explicit elements of traditional school culture are often achieved through architecture, environment and visual identity. However, on the one hand, these dominate elements are often similar among different schools; on the other hand, various schools cannot utilize these elements to influence students and audiences due to the lack of in-depth interpretation channel. Although there is the school badge, students do not know its meaning; although there is landscape, students do not know the origin. In such environment, students fail to fully understand school history and connotation, and cannot stimulate themselves to learn with school culture and spirit.

\subsection{Implicit culture lacks vitality}

Similarly, in terms of implicit culture, there is lack of the channel to deeply interpret school idea and spirit. The connotation of school culture rests on literal meaning, and lacks vitality. For example, many schools set up inquiry learning classroom for inquiry learning, but still explain textbooks with the traditional method. Except textbooks, students and teachers have no other channels to change the teaching mode, let alone promote students; understanding of teaching with vision, auditory sense and other sense organs. Seeing from textbook carrier, traditional textbooks are restricted, and can easily lead to narrowing knowledge scope. In modern education, many teachers are used to textbook-based teaching and experience-based teaching. So, the process of contacting knowledge is point-to-point communication. Students' scope of knowledge is solidified and limited subtly. Some teachers do not realize that in the new age, teaching cannot meet basic knowledge transfer. It is required to focus on teaching content and enhance learning breadth and depth.

\subsection{School teaching carrier is disconnected with the age}

Existing teaching carrier of traditional school culture is old-fashioned, and difficult to connect with the age. For first-tier cities, multimedia classroom is standard configuration. But for learners in the second-tier and third-tier cities, teaching equipment is old-fashioned, and original "blackboard teaching" is still applied. In such case, it is very hard for students to grasp the latest change information in the society. Thus, the gap with students in the first-tier cities increases. If things go on like this, the information gap among people will become larger and larger in the information age.

\section{Feasible strategies in current stage}

For the above school culture problems, we consider the brand-new school culture system can be constructed through development and application of immersive media content. Main techniques of immersive media include VR, augmented reality (AR) and H5 internet technology. These can integrate virtual objects and true environment, bring more learning joys for students through strong interactions, provide students with new learning media and learning experience and promote students to carry out mobile learning, independent study, project learning and maker learning under the cheerful state. Therefore, we will combine VR technology to improve the problems in school culture system. The detailed thoughts are as follows:

\subsection{To create extension channels of dominate and implicit cultures with VR and AR}

With AR and VR, we can develop immersive media content for each carrier in traditional school culture. Once we scan explicit culture carriers such as landmark building and landscape sculpture, video, picture, text and VR content will be played. Students can understand uniqueness and origin of school culture through the process. Similarly, such transformation is also conducted in classroom. After students wear VR equipment, they enter a virtual scene. For example, in English classroom, we can simulate the scene of living in US and experience American folk culture and pure American-style pronunciation. With the intelligent equipment, students can directly dialogue in English. Learning in 
such specific environment is more interesting than teachers' explanation in classroom. Besides, we can experience what we cannot experience in traditional classroom.

\subsection{To apply H5 technology to make carriers on the textbook and expand knowledge scope}

Through VR content development on the textbook, silent reading materials which are difficult to understand can be processed to generate audio books and reading materials with pictures. Then, H5 technology can be applied to concentrate VR video content and generate QR code which is set up in the corresponding position of textbook. For the content difficult to understand, students can enter audio/video learning interface through scanning QR code. In this page, we can view video, listen to music and play games to deeply learn culture content. Through deep interpretation of texts and pictures on the textbook via the video, students can form directly inquiry learning.

\subsection{To introduce e-bag in classroom to enrich teaching means}

E-bag as an internet product devoted to improving Chinese education informatization and promoting cooperation efficiency of family and school has been widely applied and popularized in developed cities such as Beijing, Shanghai and Shenzhen ${ }^{[4]}$. Besides, popularization work has been conducted in Chinese western region. Some small towns are also using e-bag. E-bag is a student-oriented digital teaching and learning platform which takes personal electronic terminal and network learning resource as the carrier, passes through each learning link of preview, class attending, assignment, tutoring and evaluation, and covers pre-class, in-class and after-class learning environment $^{[5]}$. The popularization of e-bag can greatly drive development of immersive school culture, promote Chinese education reform, adapt to requirements of information age and cultivate innovation-type practice talents.

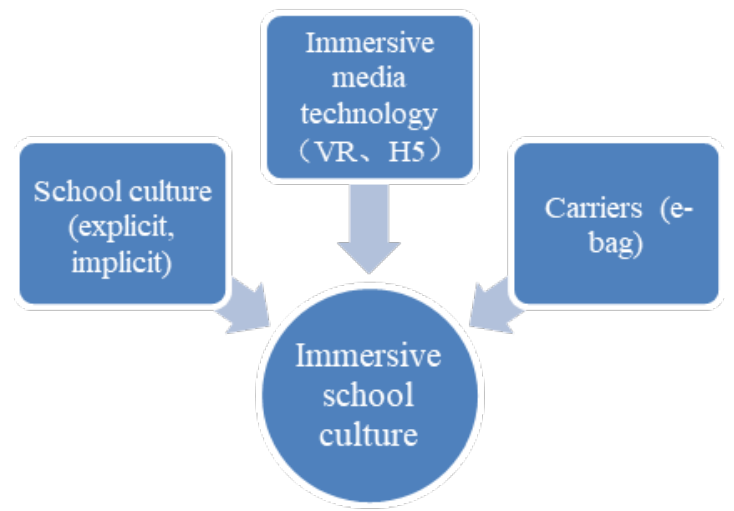

Fig.1. Immersive school culture system

\section{Future development trend of immersive school culture system}

Based on the development trend of technology, we can make the reasonable speculations. In the future, VR and AR will be combined with more high-tech elements such as artificial intelligence, cloud computing, big data and mobile technology. With the development of VR and AR, its development prospect in educational field will be broader and broader, and its combination with education will be more reasonable and scientific.

\subsection{Immersive future school}

In the future, schools will create the immersive environment and start the brand-new teaching mode. In outdoor environment, students can read the content produced by H5 technology through scanning school badge, sculpture or school architecture with AR technology to deeply interpret school connotation. In indoor environment, students can independently learn the theme content at the corridor, and corner and in the classroom through the intelligent equipment. In the immersive classroom, students can listen to professors' lectures in US or let the professor answer questions face to face. To achieve these, students just need to wear VR-related equipment. Moreover, students can 
sit in the same space with classmates with different skin color from different countries, learn the course of the same professor and gain the same credit. Students do not need to study abroad at a high cost, which saves time and money. Students just need to wear relevant devices and communicate face to face to as to better promote education and teaching fairness.

\subsection{Immersive future course}

In future teaching classroom, both students and teachers are learners. For instance, when learning the poems of Tao Yuanming, students and teachers will come to the shed of Tao Yuanming and feel the beautiful scenery "As I pick chrysanthemums beneath the eastern fence, my eyes fall leisurely on the Southern Mountain” and rural life. In VR immersive system course, teachers need to set Q \& A mode and interaction mode in simulation teaching and let students really feel they are learning Chinese in ancient times. Besides in the system, H5 can be used for backstage data statistics and observation to find out the defects in learning.

\subsection{H5 teaching management}

In big data age, teachers, students and parents can be inseparable via the mini program developed with $\mathrm{H} 5$ technology. In the strong backstage data of H5, teachers can pay attention to students' class participation and assignment completion, while parents can observe teachers' teaching and students' conditions in school. The communication between parents and teachers is no longer unilateral feedback information of teachers and passive reception of parents. Teachers and parents jointly feed information back and promote children's growth.

\section{Summary}

Artificial intelligence, big data analysis and VR education are called three major technical innovation directions which influence the future ${ }^{[5]}$. The extensive application of AR and VR in classroom teaching has great significance for implementing the imagination of Ministry of Education about "future school development" and "wisdom classroom reform". Of course, we also should realize what VR and AR learning environment brings us is not just a technical platform or tool, and a new teaching mode and teaching method will be generated. So, we should seize the opportunity and drive virtual education pace. Meanwhile, in view of potential instability of these technologies, we also need to prepare for rising to future challenges.

\section{Acknowledgement}

This research was financially supported by the 2016 National Innovation and Entrepreneurship Training Program for College Students (Grant NO. 201614388076).

\section{References}

[1] Tang Hanwei, Thoughts on school culture construction - problems in school culture construction, Research in Education Development, 2012,32(Z2):84-89.

[2] Wu Lihua, On school culture construction of vocational high schools, Zhong Guo Ning Cun Jiao $Y u, 2008(Z 2): 94-95$.

[3] Li Xunxiang, You Lixue, Opportunities, challenges and countermeasure of practice teaching in VR age, Modern Educational Technology, 2017,27(07):116-120.

[4] Lian Yunmei, E-bag classroom teaching based on IRS real-time feedback system, China Education Info, 2013(16):41-43.

[5] Xie Lihong, E-journal based on e-bag: Teacher Version, 2016, 36 (17).

[6] Wang Tongju, Application and prospect of AR and VR technology in teaching, Digital Education, 2017,3(01):1-10. 